\title{
Long Transients Near the Ghost of a Stable State in Eutrophic Shallow Lakes with Fluctuating Water Levels
}

\author{
G. J. Van Geest, ${ }^{1,3, *}$ H. Coops, ${ }^{2}$ M. Scheffer, ${ }^{1}$ and E. H. van $\mathrm{Nes}^{1}$
}

\begin{abstract}
${ }^{1}$ Department of Aquatic Ecology and Water Quality Management, Wageningen University and Research Centre, P.O. Box 8080, 6700 DD, Wageningen, The Netherlands; ${ }^{2} W L /$ Delft Hydraulics, P.O. Box 177, 2600 MH Delft, The Netherlands; ${ }^{3}$ Department of Food Web Studies, NIOO-KNAW, Rijksstraatweg 6, 3631 AC, Nieuwersluis, The Netherlands
\end{abstract}

\begin{abstract}
Alternative stable states in shallow lakes have received much attention over the past decades, but less is known about transient dynamics of such lakes in the face of stochastic perturbations such as incidental extremes in water levels driven by climatic variability. Here, we report on the ecosystem dynamics of 70 lakes in the floodplains of the Lower Rhine in The Netherlands from 1999 to 2004. In any particular year, most lakes were either in a macrophyte-dominated clear state or in a contrasting state with turbid water and sparse submerged macrophyte cover. Macrophyte dominance was positively related to the occurrence of drawdown, and negatively to lake surface area and mean depth. We did not find a relation with nutrient levels. Remarkably, shifts between the two contrasting states were common, and episodes of low water levels appear to be an important external driver. A dry period before our study and the exceptionally dry summer of 2003 caused widespread drawdown of floodplain lakes, resulting in establishment of submerged macrophytes in the
\end{abstract}

\section{INTRODUCTION}

The theory of alternative stable states suggests that shallow lakes will usually be either clear and mac-

Received 18 November 2005; accepted 6 July 2006; published online 3 April 2007.

*Corresponding author; e-mail: g.vangeest@nioo.knaw.nl,

H.Coops@riza.rws.minvenw.nl next year upon refill. In the 4 years without drawdown, many lakes returned to a macrophytepoor turbid state. Although some lakes turned turbid again quickly, others took several years to shift into the turbid state. A model analysis suggests that such prolonged transient vegetated states may be explained by the fact that the system dynamics slow down in the vicinity of the "almost stable" macrophyte-dominated state. Such a "ghost" of an equilibrium causes the system to stick around that state relatively long before slipping into the only true stable state. Our results support the idea that transient dynamics rather than equilibrium may be the key to understanding the overall state of some ecosystems. A practical implication of our findings is that artificial stabilization of the water level in shallow lakes may have been an important factor aggravating the permanent loss of submerged macrophytes due to cultural eutrophication.

Key words: submerged macrophytes; water level fluctuations; drawdown; alternative stable states. 


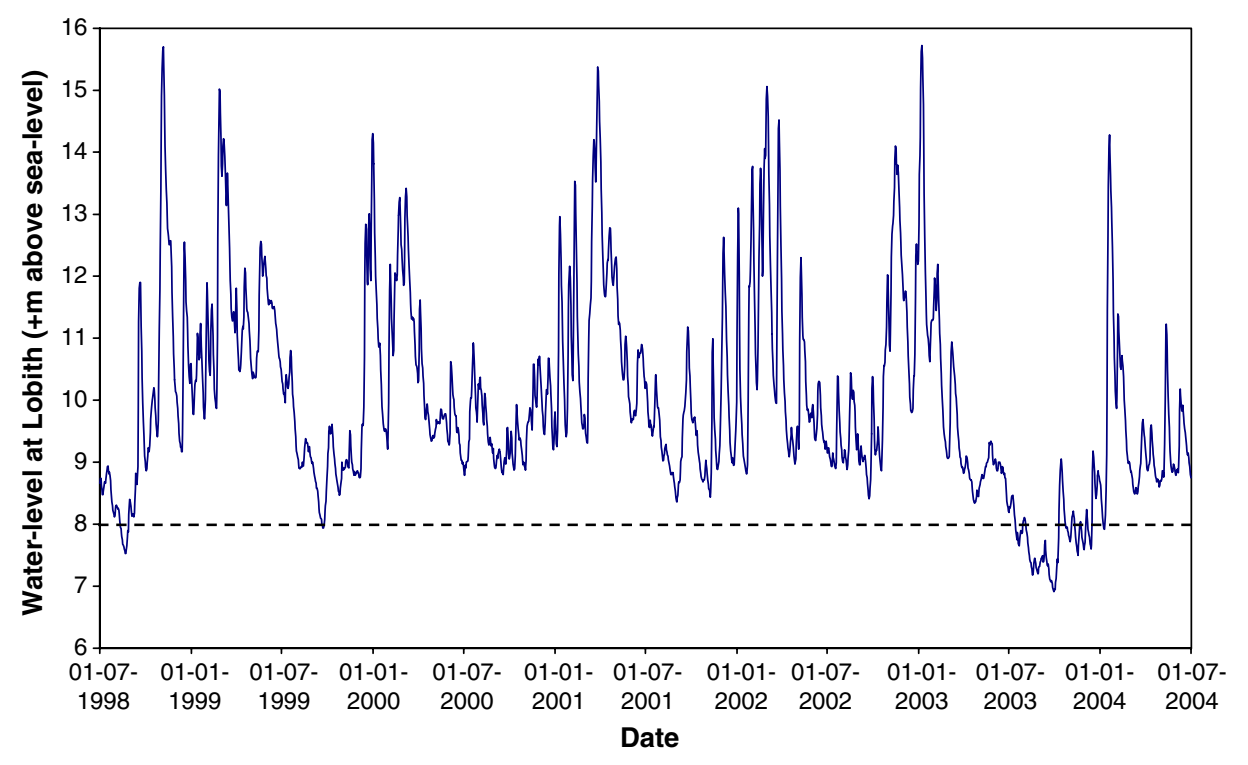

Figure 1. River water levels in the lower Rhine at the entrance of the river in The Netherlands near Lobith $(\mathrm{m}+$ sea level) during 19982004. Note that prolonged periods with water levels below $8.00 \mathrm{~m}$ at Lobith are associated with extremely low water levels in many floodplain lakes along the Lower Rhine. to another. Changes in submerged macrophyte cover have often been explained as a result of variable nutrient loads (Hough and others 1989; Tracy and others 2003). Increased nutrient loads may result in a reduced cover of submerged macrophytes, due to a decreased transparency resulting from enhanced algal growth or higher concentrations of suspended sediments (Jeppesen and others 1997; Scheffer 1998). However, strong changes in macrophyte cover may also be caused by alterations in the water level (Wallsten and Forsgren 1989; Engel and Nichols 1994). An increase in water level reduces light availability, thereby limiting submerged macrophyte growth (Blindow and others 1993). By contrast, low water levels may stimulate submerged macrophyte expansion because of increased light availability to the lake bottom. Enhanced germination rates of macrophytes from seed banks upon resubmersion of temporarily exposed lake sediments may also play a role (Havens and others 2004). Furthermore, low water levels are likely to result in increased mortality of fish, which may stimulate macrophyte growth through a range of mechanisms (Scheffer 1998; Jones and Sayer 2003). Many well-studied shallow lakes have artificially stabilized water levels, and therefore lack the influence of alternating high and low water levels on submerged macrophytes. Hence, water level fluctuations have received far less attention compared to the effects of nutrients in explaining temporal changes of submerged macrophyte cover.

The present study explores the importance of water level fluctuations, lake morphometry and nutrient levels on inter-annual shifts in submerged macrophyte cover for a set of 70 floodplain lakes along the Lower Rhine during 1999-2004. We also use a simple model to explore how the observed large inter-annual fluctuations of macrophyte cover may relate to the alternative states theory (Scheffer 1998; Scheffer and others 1993).

\section{Study Area}

The Lower Rhine in The Netherlands consists of three branches, called Waal, IJssel, and Neder-Rijn. In the floodplains of these three branches, 70 lakes were selected for the present study. At the location where the Rhine enters The Netherlands, the discharge varies annually between about 800 and $12,000 \mathrm{~m}^{3} \mathrm{~s}^{-1}$, resulting in water level fluctuations of up to $8 \mathrm{~m}$ in the main channel. Typically, the maximum annual river discharge occurs in winter and the minimum in autumn, although high and low discharges may occur at any moment throughout the year (Buijse and others 2002).

In some years, prolonged periods of extremely low river water levels occur at the end of the growing season. Because water levels in floodplain lakes are strongly linked to the water level in the river through groundwater flow (Van Geest and others 2005), periods of low water level in the river may result in partial or complete natural drawdown of the lakes as well. In the period 1999-2002, no prolonged periods of low river water level occurred (Figure 1). Consequently, almost none of the investigated lakes were drawn down during these years (Figure 2A). By contrast, the river dropped to low levels in the fall of 1998 and to extremely low levels in the fall of 2003. In the latter year, the lowest river water level measured ever 

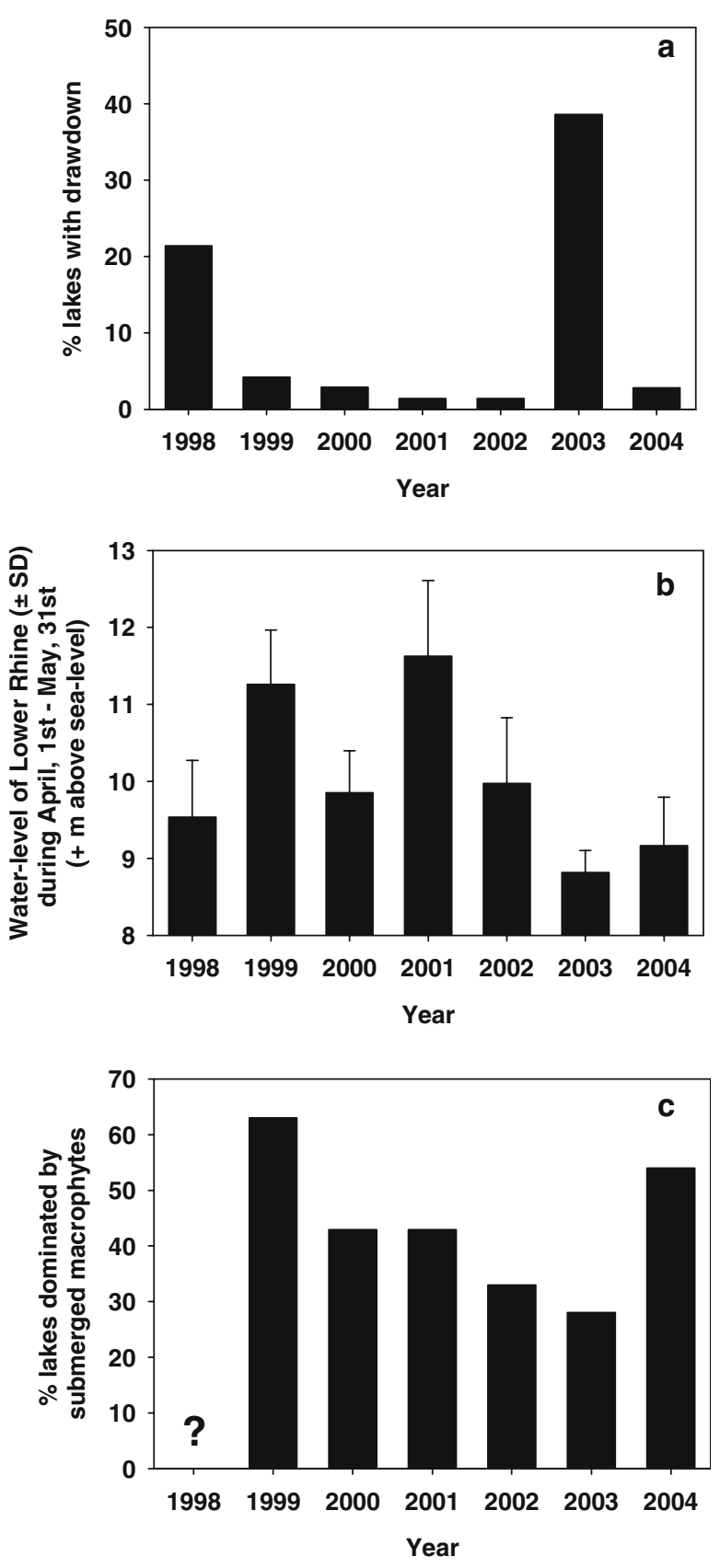

since the start of the monitoring in 1824 occurred in early October 2003. As a result, many floodplain lakes along the Lower Rhine were drawn down in late 2003 (Figure 2A). In addition, there were large inter-annual differences in mean spring water levels in the Lower Rhine. In 1999 and 2001, spring water levels in the main channel were high, whereas during 2000 and 2002-2004, they were relatively low (Figure $2 \mathrm{~B}$ ).

\section{Materials and Methods}

In 70 lakes in the floodplains of the Rhine branches (Waal, IJssel, and Neder-Rijn: 33, 20, and 17 lakes,
Figure 2. A Percentages of lakes with drawdown area of $50 \%$ or more of surface area during 1998-2004. For 1999-2004, the data are based on visual observations. For 1998, the number of drawn down lakes were calculated according to Coops and Van Geest (2005) in combination with visual observations of 22 lakes in that year. B Spring water level ( $m$ above sea level) at Lobith (entrance point of Lower Rhine in The Netherlands) \pm SD during April, 1st-May, 31st of 1998-2004. C Percentage lakes dominated by submerged macrophytes (cover $\geq 20 \%$ of lake surface area) during 19992004. No data were available for 1998. Because five lakes were already dried out during the sampling period of aquatic macrophytes in 2003, this figure is based on 65 lakes for the year 2003 and 70 lakes for 1999-2002, and 2004. In this figure, inter-annual changes in the percentage of macrophyte-rich lakes reflect the net balance between forward and backward switches (see Table 4).

respectively), submerged macrophyte cover was assessed once per year (July-early August) from 1999 to 2004. In each lake, the proportion of the total open-water surface covered by submerged macrophytes was estimated visually. For each lake, estimates of inundation duration and surface area were obtained from GIS-maps (RIZA, The Netherlands). For inundation duration, the estimates were categorized in five classes, and were based on the geographical height of the floodplains and the longterm (1900-1995) water level regime of the river. For each class of inundation duration, the median value of the range was used in the statistical analyses: (class I) average inundation duration less than 2 days $\mathrm{y}^{-1}$ : median value equals 1 day $\mathrm{y}^{-1}$; (class II) 2-20 days $y^{-1}$ : median value equals 10 ; day $y^{-1}$ (class III) 20-50 days $\mathrm{y}^{-1}$ : median value equals 35 days $\mathrm{y}^{-1}$; (class IV) 50-150 days $\mathrm{y}^{-1}$ : median value equals 100 days $\mathrm{y}^{-1}$; (class $\mathrm{V}$ ) more than 150 days $\mathrm{y}^{-1}$ : median value equals 258 days $\mathrm{y}^{-1}$ (Table 1). Nevertheless, despite these large differences in average inundation duration, during each winter in the study period almost all studied lakes were inundated by the river through surface overflow, yet none of the lakes were permanently connected to the main channel.

The approximate lake age was derived from historical topographical maps (Table 1). Reliable estimates of lake age could be made up to 300 years; older lakes were regarded as 300 years old. The uncertainty of the lake age estimation was about 1 year for lakes that were newly dug after 1980, 3-7 years for lakes originating from the period 1910-1980, and 10-25 years for lakes prior to 1910 .

During the fieldwork the prevailing land use in the adjacent floodplain (presence of trees, cattle 
Table 1. Number of Lakes, Minimum, Maximum, and 25, 50 And 75 Percentile Values of Environmental Variables

\begin{tabular}{|c|c|c|c|c|c|c|}
\hline & $N$ lakes & Min. & $25 \%$ & $50 \%$ & $75 \%$ & Max. \\
\hline Lake age (year) & 70 & 1 & 32 & 109 & 188 & 300 \\
\hline Surface area (ha) & 70 & 0.02 & 0.41 & 1.59 & 2.00 & 15.0 \\
\hline Mean lake depth (m) & 70 & 0.13 & 0.76 & 1.21 & 1.58 & 5.16 \\
\hline Inundation duration $\left(\right.$ day $\mathrm{y}^{-1}$ ) & 70 & 1 & 11 & 50 & 100 & 258 \\
\hline Decrease in water level July-Oct 1999 (m) & 70 & -0.21 & 0.30 & 0.58 & 0.84 & 1.42 \\
\hline Probability for lake drawdown & 70 & -0.32 & 0.20 & 0.36 & 0.51 & 0.96 \\
\hline Presence of trees & 70 & 0.0 & 0.0 & 0.2 & 0.5 & 1.0 \\
\hline Cattle grazing & 70 & 0.0 & 0.0 & 0.59 & 1.0 & 1.0 \\
\hline Use of manure & 70 & 0.0 & 0.0 & 0.6 & 1.0 & 1.0 \\
\hline Total N $\left(\mathrm{mg} \mathrm{l}^{-1}\right)$ & 67 & 0.48 & 0.97 & 1.30 & 1.54 & 3.40 \\
\hline Total $\mathrm{P}\left(\mathrm{mg} \mathrm{l}^{-1}\right)$ & 67 & 0.04 & 0.12 & 0.22 & 0.25 & 0.86 \\
\hline
\end{tabular}

access to the shoreline, use of manure on adjacent land) was recorded. For these variables the following categories were used: presence of trees: ( 0 , shoreline length for $<25 \%$ covered by trees; 0.5 , shoreline covered for $25-75 \%$ by trees; 1 , shoreline covered $>75 \%$ by trees); cattle grazing: (0, cattle access to $0-25 \%$ of perimeter; $0.5,25-75 \%$ of perimeter; $1,>75 \%$ of perimeter); use of manure: $(0$, no manuring of adjacent land; $0.5,>0-50 \%$ of adjacent land; 1, 51-100\% of adjacent land). For 67 of the 70 floodplain lakes sampled in 1999, samples for total $\mathrm{N}$ and total $\mathrm{P}$ in the water phase were taken according to Roozen and others (2003).

In July 1999, water depths were measured at several locations in each lake. In addition, the seasonal water level change $\left(\mathrm{WL}_{\mathrm{J}-\mathrm{O}}\right)$ was assessed using a marked rod in each lake that was measured in July and October 1999. The ratio between $\mathrm{WL}_{\mathrm{J}-\mathrm{O}}$ and maximum lake depth $\left(D_{\text {maxJ }}\right)$ in 1999 was calculated as an indicator of the likelihood of lake drawdown (a value of one implies exposure of the entire lake bottom in 1999). To check if this ratio was a reliable indicator for lake bottom exposure in other years, the proportion of the drawdown area of each lake was estimated visually during October 2003, which coincided with the end of a prolonged period of extremely low water levels in the main channel. Overall, the indicator for lake drawdown was highly correlated to percentage lake drawdown in 2003 (Spearman $R=0.65, P<0.000001$ ), indicating that the ratio $\mathrm{WL}_{\mathrm{J}-\mathrm{O}} / D_{\max J}$ can be used as a relative indicator for the likelihood of lake drawdown in other years.

\section{Data Analysis}

Data on macrophyte cover of the lakes were available for 70 lakes for the years 1999-2002, and 2004. In 2003, however, macrophyte cover could only be determined in 65 lakes, as the remaining 5 lakes were already drawn down when the macrophytes were sampled, due to the extremely low river water levels in this year. Multiple linear regression analysis (selection procedure: stepwise, forward) was used to evaluate the relationship between eight environmental variables (Table 2) and the number of years that the lakes were rich ( $\geq 20 \%$ cover) in submerged macrophytes (Jongman and others 1995). For macrophyte-rich lakes, we used a threshold value of $20 \%$ cover of lake surface area, although threshold values of 20, 30, and $40 \%$ submerged macrophyte cover yielded similar results during logistic regression analyses with a data set of 215 lakes along the Lower Rhine (including our study lakes; Van Geest and others 2003). For all statistical analyses, we used data of 70 lakes in 5 years (1999-2002, and 2004). We checked if similar results were obtained if the dataset of 6 years (including 2003) with 65 lakes was used. All statistical analyses were performed using the software program STATISTICA Release 7, Statsoft Inc.

\section{A Model}

To explore how non-equilibrium dynamics of lakes may be linked to the theory of alternative stable states, we analyzed a model of Scheffer (1998), describing the relation between macrophytes and turbidity in shallow lakes. The basis of this model is the well-studied positive feedback of submerged macrophytes to their own growth, described by empirically derived effects of turbidity on macrophytes and vice versa. The turbidity of the lake without macrophytes is assumed to be dependent on the nutrient status (a single parameter). The presence of macrophytes reduces the equilibrium turbidity as a Monod equation, for data see Scheffer 
Table 2. Eight Independent Environmental Variables used in Multiple Linear Regression Analysis to Predict the Number of Years that the Lakes were Dominated by Submerged Macrophytes during 1999-2002 and 2004

\begin{tabular}{|c|c|c|}
\hline Variable & Unit & Comments \\
\hline Lake age ${ }^{1}$ & year & For accuracy: see Materials and methods \\
\hline Lake surface area $^{1}$ & ha & Surface area of lake at start of growing season \\
\hline Mean lake depth ${ }^{1}$ & $\mathrm{~m}$ & $\begin{array}{l}\text { Calculated from } 5 \text { to } 31 \text { water depth } \\
\text { measurements in July } 1999 \text { in each lake }\end{array}$ \\
\hline Inundation duration $^{1}$ & day $y^{-1}$ & Long year average 1990-1995 \\
\hline Probability for lake drawdown & & $\begin{array}{l}\text { Index for probability of lake drawdown } \\
\text { (for calculation: see Materials and methods) }\end{array}$ \\
\hline Presence of trees along shoreline & Categories & See Materials and methods \\
\hline Access of cattle to shoreline & Categories & See Materials and methods \\
\hline Use of manure on adjacent land & Categories & See Materials and methods \\
\hline
\end{tabular}

(1998). On the other hand, turbidity has a negative effect on the macrophyte abundance. Above a certain critical turbidity, the lake becomes vegetated. This is formulated as a sigmoidal increase in macrophyte cover with water clarity. Scheffer (1998) analyzes the equations of the nullclines of this model graphically, but the model can be made dynamic by assuming that both macrophyte cover $(V)$ and vertical light attenuation $(E)$ approach their equilibrium logistically (Van Nes and Scheffer 2005):

$$
\begin{aligned}
\frac{\mathrm{d} V}{\mathrm{~d} t} & =r_{v} V\left(1-V \frac{h_{E}^{p}+E^{p}}{h_{E}^{p}}\right) \\
\frac{\mathrm{d} E}{\mathrm{~d} t} & =r_{E} E\left(1-\frac{E}{E_{0}} \frac{h_{v}+V}{h_{v}}\right)
\end{aligned}
$$

Although the feedback between macrophytes and turbidity is not described mechanistically, the parameters of this model can well be interpreted biologically (Scheffer 1998). The vertical light attenuation without macrophytes is in the model a fixed parameter $\left(E_{0}\right)$. In reality, this can be related to algal growth (nutrient status) and resuspension of sediments in the lake (and indirectly with lake size), but these complex mechanisms are not modelled. The parameter $h_{E}$ is the critical light attenuation around which the lake becomes vegetated (this parameter is inversely related to the depth of the water column). The power $p$ determines whether the lake becomes vegetated all at once or not. If the water depth is uniform in the lake, vegetation will start growing in the whole lake at a certain turbidity. This is reflected in a high $p$. If there are shallow parts and deeper parts vegetation will appear more gradually, and first in the shallow parts (low $p$ ). The value of $p$ has an important effect on the range of parameter values over which the system has alternative stable states (the so-called "hysteresis"). At default we use a moderately high value of 4 , as this value produces a hysteresis that corresponds well to what is observed in other shallow lakes (Van Nes and others 2002; Meijer 2000; Van Nes and others 2007). The parameter $h_{V}$ determines the macrophyte cover where the light attenuation is reduced by $50 \%$. This parameter will depend, among other things, on the plant species. Finally, the rate parameters $r_{V}$ and $r_{E}$ determine how fast macrophytes and turbidity approach their equilibrium.

To mimic stochastic fluctuations in water level we added 'noise' to the parameter $h_{E}$ in some analyses. We used the recurrent relation of Hasselmann (1976) on a daily basis to generate red noise (that is, noise with autocorrelation) with an approximate period of $\lambda$ days $(\lambda>1=$ red noise $)$ :

$$
h_{E(t)}=\left(1-\frac{1}{\lambda}\right)\left(h_{E(t-1)}-\overline{h_{E}}\right)+\overline{h_{E}}+\beta \varepsilon
$$

In which $\epsilon$ is the number drawn from a standard normal distribution and $\beta$ is determining the amount of noise and is the average water depth. The parameters $\lambda$ and $\beta$ were adjusted to get a pattern that was roughly comparable to the water level fluctuations in the river (Figure 1).

\section{RESULTS}

\section{Field Patterns}

Our data revealed large inter-annual differences in cover of submerged macrophytes (Figure 3). Lakes differed also widely in number of years that they were dominated (cover $\geq 20 \%$ ) by submerged 


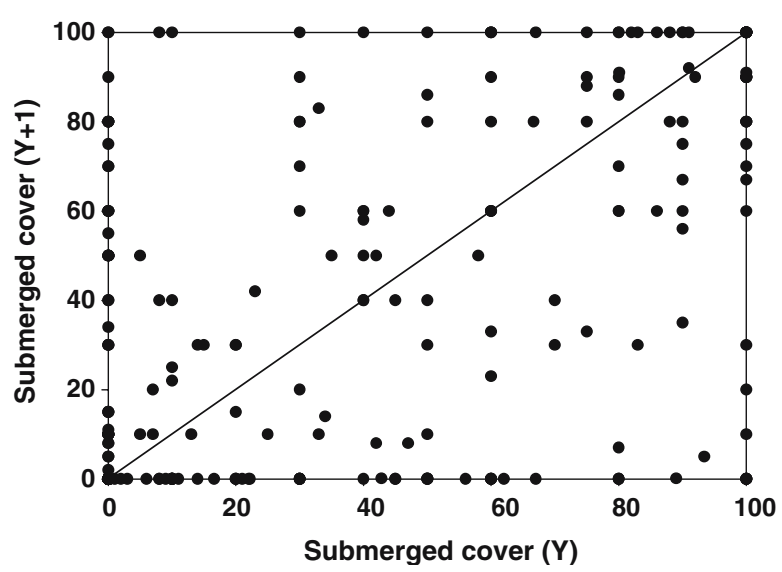

Figure 3. Percentage cover of submerged macrophytes in lakes in 1 year $(Y)$ relative to the cover of submerged macrophytes in the next year $(Y+1)$ during 1999-2004. The diagonal line in the graph represents values of zero change in submerged macrophyte cover between years.

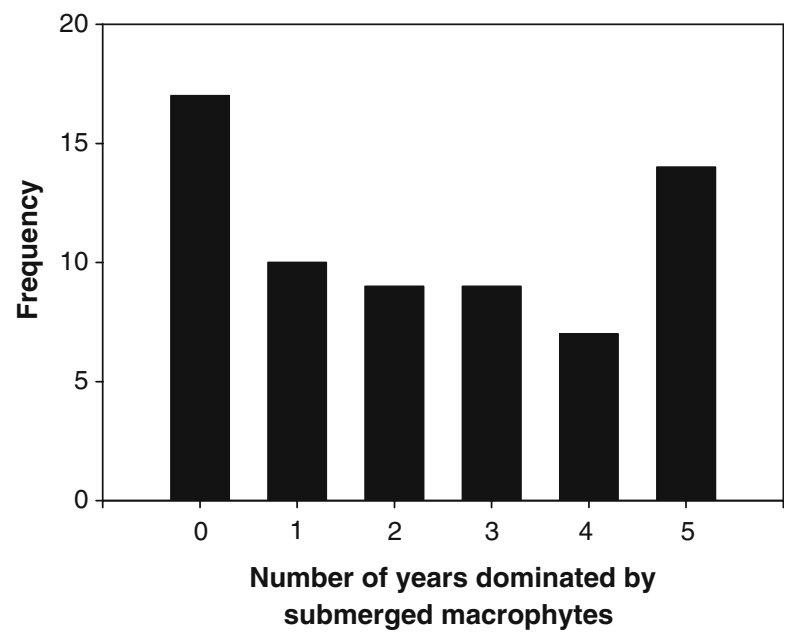

Figure 4. Frequency distribution of the number of years that the lakes were dominated by submerged macrophytes (cover $\geq 20 \%$ ) during 1999-2002, and 2004 ( $n=70$ lakes $)$.

macrophytes (Figure 4). Multiple linear regression analysis on the 5-year dataset of 70 lakes indicated that the number of years with macrophyte dominance in the lakes was higher in lakes with a higher probability of drawdown, whereas lakes had fewer years with high macrophyte cover if they had a larger lake surface area, mean depth, inundation duration, and cover of trees along the shoreline $\left(R_{\text {adj }}^{2}=0.47\right.$; Table 3$)$. Similar results were obtained when the dataset of 65 lakes during 6 years was used (including the year 2003, see Materials and methods; $R_{\text {adj }}^{2}=0.48 ; \quad F(5,59)=12.692$; $P<0.00001)$.
For each pair of years, there was a group of lakes that shifted from a macrophyte-poor to a macrophyte-rich state (forward switches), and vice versa (backward switches) (Table 4). During 1999-2003, backward switches predominated, and the percentage of macrophyte-rich lakes dropped from $63 \%$ in 1999 to $28 \%$ in 2003 . During 2003-2004 however, the reversed pattern was observed, and the number of macrophyte-rich lakes sharply increased to $54 \%$ (Figure 2C). Years with a high number of macrophyte-rich lakes (for example, the first year, 1999 and the last year 2004) were preceded by a high incidence of drawdown (21 and $39 \%$ of the study lakes in 1998 and 2003, respectively), whereas the percentage of drawn down lakes was very low $(<5 \%)$ in other years (Figure $2 \mathrm{~A}$ ). By contrast, if the water level in the main channel is taken as an indicator for lake water levels, there was no relationship between spring water level and number of macrophyte-dominated lakes between 1999-2004 (Figure 2).

For further analysis, the lakes were divided into three categories: permanently macrophyte-rich, permanently macrophyte-poor, and shifting lakes. The latter category represented lakes that changed from at least $20 \%$ submerged macrophyte cover to less than $20 \%$ for at least one of the years during the study period (1999-2004). Between these three categories, no significant differences for total nitrogen $\left[\left(F_{2,61}\right)=0.4101, \quad P=0.67\right]$ and total phosphorus levels $\left[\left(F_{2,61}\right)=0.7857, P=0.46\right]$ were detected.

By focusing on the fate of the lakes that had a transient dominance by macrophytes from the start of our study period, the progressive shift to the turbid state over the first years of our study was even more dramatic. It appeared that smaller lakes in this group remained dominated by macrophytes for a longer period of time than larger ones (Figure 5).

\section{Model Results}

At first sight, the frequent shifting of the lakes in this study may seem in contradiction with the alternative state theory (Scheffer and others 1993), which predicts one or two stable states depending on the nutrient state. Switching between these states is expected to be rare. However, the conditions in the floodplain lakes are highly dynamic, whereas the alternative state theory focuses on ecosystems in equilibrium under constant or slowly changing conditions. To see how the theory might be modified for highly dynamic situations, we have explored the transient states of a macrophyte- 
Table 3. Results of Stepwise (Forward) Multiple Linear Regression Analysis in a Set of 70 Lakes between Environmental Lake Characteristics and Number of Years that the Lakes were Dominated by Submerged Macrophytes during 1999-2002 and 2004

\begin{tabular}{|c|c|c|c|c|c|}
\hline & Stand. beta & Std. error of beta & $B$ & Std. error of $B$ & $P$-level \\
\hline Intercept & & & 3.32 & 0.48 & $<0.000001$ \\
\hline Inundation duration $^{1}$ & -0.34 & 0.09 & -0.43 & 0.12 & $<0.001$ \\
\hline 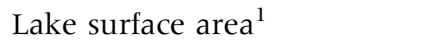 & -0.23 & 0.10 & -0.34 & 0.14 & $<0.05$ \\
\hline Mean lake depth ${ }^{1}$ & -0.44 & 0.10 & -1.46 & 0.32 & $<0.0001$ \\
\hline Presence of trees & -0.25 & 0.09 & -1.32 & 0.47 & $<0.01$ \\
\hline Probability for lake drawdown & 0.21 & 0.09 & 1.63 & 0.71 & $<0.05$ \\
\hline
\end{tabular}

Dominated by submerged macrophytes is equal to cover of $20 \%$ or more. $N_{\text {tot }}=5$ years; $R_{\text {adj }}^{2}=0.47 ; F(5,64)=13.025 ; P<0.00001$, std. error of estimate $=1.3972 ;$ stand. Beta $=$ standardized beta values; $B=$ unstandardized beta values.

${ }^{1} \ln (x)$-transformed.

Table 4. Percentage of Inter-Annual Shifts from Macrophyte-Rich to Macrophyte-Poor Lakes (Backward Switches) and Vice Versa (Forward Switches) during 1999-2004

\begin{tabular}{lcc}
\hline Pair of years & $\begin{array}{l}\text { Backward } \\
\text { Switches }\end{array}$ & $\begin{array}{c}\text { Forward } \\
\text { Switches }\end{array}$ \\
\hline $1999-2000$ & 27 & 7 \\
$2000-2001$ & 7 & 7 \\
$2001-2002$ & 16 & 6 \\
$2002-2003$ & 12 & 6 \\
$2003-2004$ & 3 & 28
\end{tabular}

Macrophyte-rich lakes had cover of $20 \%$ or more. Macrophyte-poor lakes had cover of less than $20 \%$. For each pair of years, the comparison is based on 70 lakes, except for 2002-2003 and 2003-2004 ( $n=65$ lakes), because in 2003 five lakes were already dried out during the sampling period of aquatic macrophytes.

turbidity model, which described the alternative states in shallow lakes.

For the default parameter setting, the model has alternative states over a range of values of nutrient loading (Figure 6A). To explore transient dynamics we let simulations start at a clear vegetated initial state and follow how the model approaches equilibrium depending on the nutrient status $\left(E_{0}\right)$ of the lake (Figure 6B). At moderately high nutrient loading $\left(E_{0}=6\right)$ the clear vegetated state is stable and the system will quickly settle to the vegetated equilibrium. If the nutrient loading increases $\left(E_{0}=7.5\right)$ the vegetated state becomes unstable. However, close to the point where stability is lost, it takes a long time for the system to move to the macrophyte-poor state. With further increase of the nutrient level $\left(E_{0}=8,10\right)$ the system settles faster to the turbid state.

As most of the lakes in the floodplain are nutrient-rich (Table 1), we assume that many lakes are in the range with only a stable turbid state (right of the grey area in Figure 6A, for example, $E_{0}=8$ ). In this situation there is only one equilibrium. However, Figure 6B shows the transient dynamics can be slow and some lakes may remain in the macrophyte dominated state much longer than others. A disturbance such as drawdown puts them into a (unstable) clear state.

To see the cause of this effect better, one can plot the behavior of the system in a state-space (Figure 7). In a situation in which the nutrient level is only slightly too high to allow a stable clear state (arrow in Figure 6A), the nullclines of macrophytes and turbidity $\left(V^{\prime}=0\right.$ and $\left.E^{\prime}=0\right)$ are close together in the region around the former stable vegetated state. This implies a bottleneck in the phase plane with slow dynamics (dark grey island in Figure 7B). Such a remainder of a previous equilibrium is sometimes called the "ghost" of an equilibrium (Strogatz 1994), indicating that although the equilibrium itself does not exist, one can still feel its effect as the dynamics can be very slow in such a region. The ghost still attracts trajectories, and the trajectories are channelled through the bottleneck where they become slow. Consequently, depending on the initial state, the turbid equilibrium may be reached only after a long simulation time (Figure 7C). So, if such a turbid system is "disturbed", for instance by a period of high macrophyte cover and low turbidity due to drawdown, the system is predicted to remain vegetated for quite a long time as it is first attracted and slowed down by the ghost of the equilibrium. Eventually, the lake is predicted to return to the turbid, macrophyte-poor state. Figure 8 illustrates this in a stability plot of the model.

To check how the ghost phenomenon might affect ecosystem dynamics in a stochastically varying environment such as the floodplains that we studied, we exposed the model to constantly fluctuating conditions mimicked by adding red 


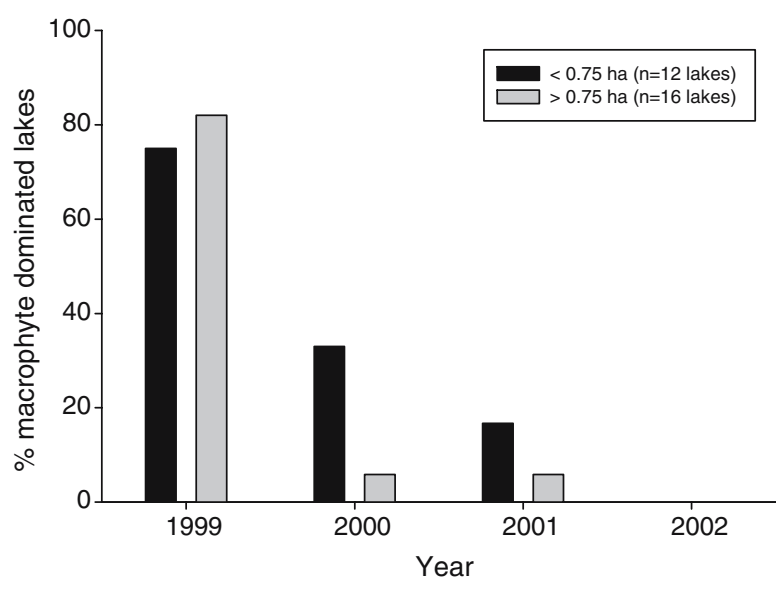

Figure 5. Percentage of the category of shifting lakes that were dominated by submerged macrophytes (cover $\geq 20 \%$ ) in succeeding years, in relation to the surface area of the lakes. In this figure, only lakes with backward switches are included (see Table 4). The percentage macrophyte dominated lakes in 2003 and 2004 was zero in both years, because none of the lakes within the shifting category were macrophyte dominated in all years during 1999-2004.

noise to the parameter $h_{E}$. This parameter represents the sensitivity of macrophytes to turbidity and should thus vary with the water level. Despite the fact that the average parameter value used allows only the turbid equilibrium to be stable, the stochastic forcing resulted in periods with prolonged macrophyte dominance at irregular intervals (Figure 9). This supports the view that unravelling the mechanisms behind non-equilibrium dynamics rather than 'stable states' are key to understanding such systems.

\section{Discussion}

The floodplain lakes in our study showed remarkably strong and frequent inter-annual shifts in macrophyte cover. This contrasts to typical case studies in the literature suggesting that most shallow lakes are either in a macrophyte-dominated clear water state or in an unvegetated turbid state, with shifts between these states being relatively uncommon (Scheffer 1998). Our results suggest that the high percentage of macrophyte-dominated lakes in 1999 and 2004 are likely the result of drawdown of many of the lakes in 1998 and 2003. In the intermediate period when drawdowns rarely occurred, there was a net tendency for lakes to lose their submerged macrophytes (Figure 2). Stimulatory effects of drawdown on submerged macrophytes have been reported in a few other studies
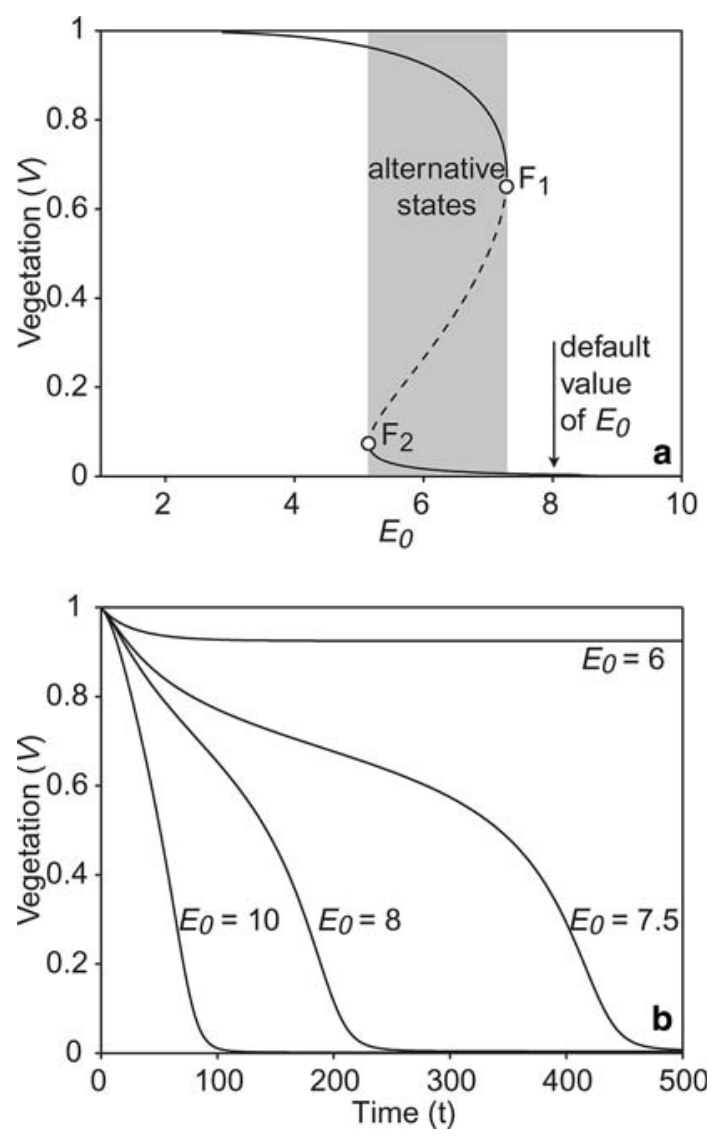

Figure 6. A The range of the parameter $E_{0}$ (light attenuation if there are no macrophytes), where there are two stable states. The arrow indicates the value of $E_{0}$ used for producing Figures 7 and 9 (Parameters: $h_{E}=2 ; h_{V}=0.2$; $\left.P=4 ; r_{E}=0.1 ; r_{V}=0.05\right) ; \mathbf{B}$ some examples of transient dynamics at different $E_{0}$. All simulations start in the clear vegetated state $(V=1, E=1)$.

(Gibbs 1973; Havens and others 2004), but received relatively little attention so far.

A puzzling aspect in our data is the apparent difference in return time to the turbid state with little or no macrophytes. Although some lakes lost their submerged vegetation already after one year, others remained vegetated several years or even throughout the study period. At first sight, an obvious explanation for this pattern would be that fish populations are wiped out, or at least severely reduced during draw-down episodes, allowing the lakes to shift to a clear and macrophyte-dominated state, whereas subsequent recolonization by fish and expansion of fish populations may take a long time, depending on colonization opportunities. However, although fish elimination will certainly play an important role, all the lakes were flooded annually during the research period giving ample opportunity for the abundant populations of bream 

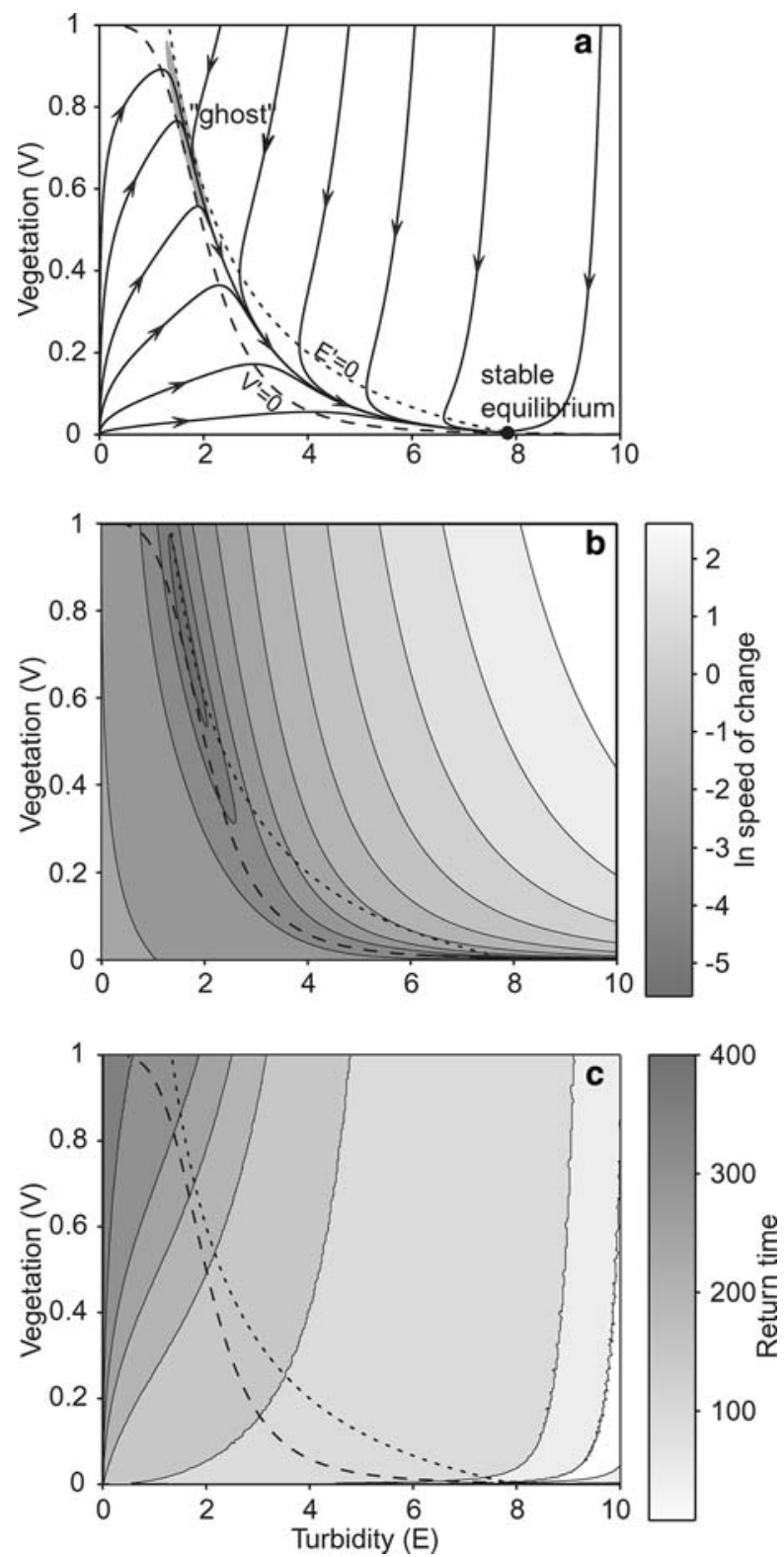

Figure 7. A The phase plane with nullclines (dotted: the turbidity nullcline; dashed: the macrophyte nullcline) and some trajectories (solid lines with arrows). B The vector sum of the relative per capita rate of the change in both state variables $\left(\right.$ day $\left.^{-1}\right)$ in the phase plane. C The time needed to reach the turbid equilibrium (days). This time was determined numerically and was defined as the time after which the rate of change was less than $10^{-3}$. Parameters: see Figure 6.

(Abramis brama) in the main channel to recolonize the lakes (Molls 1999; Grift and others 2001). Still, as discussed below, fish may well colonize some lakes more readily than others as they actively chose habitats.

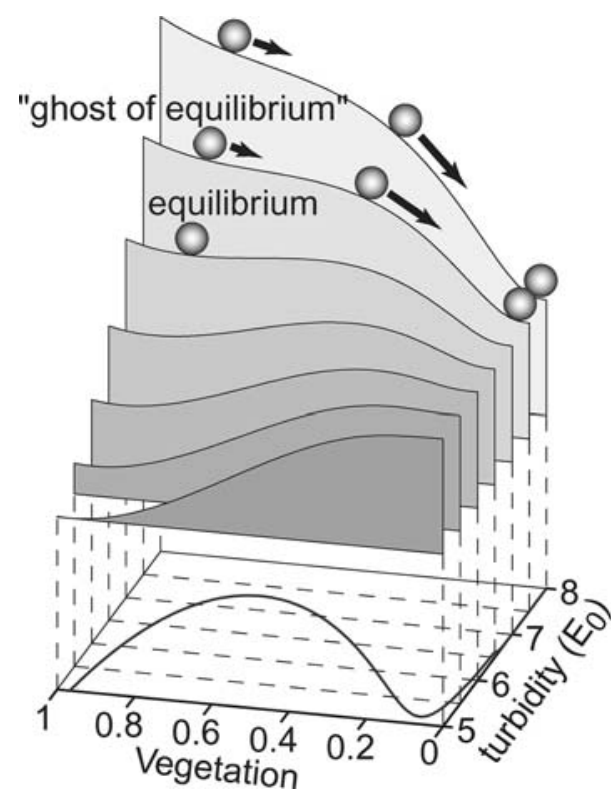

Figure 8. Stability landscape of the model. The valleys represent stable states and the marbles the current state of the lake. It should be emphasized that the marbles slide in a heavily damped way over the landscape. Near the ghost the slope is less steep, indicating that the system will change slowly there. This figure was calculated in MATLAB by solving the potential function (Strogatz 1994) of the model (which has to be made one-dimensional, we did this by assuming that the turbidity was always in equilibrium).
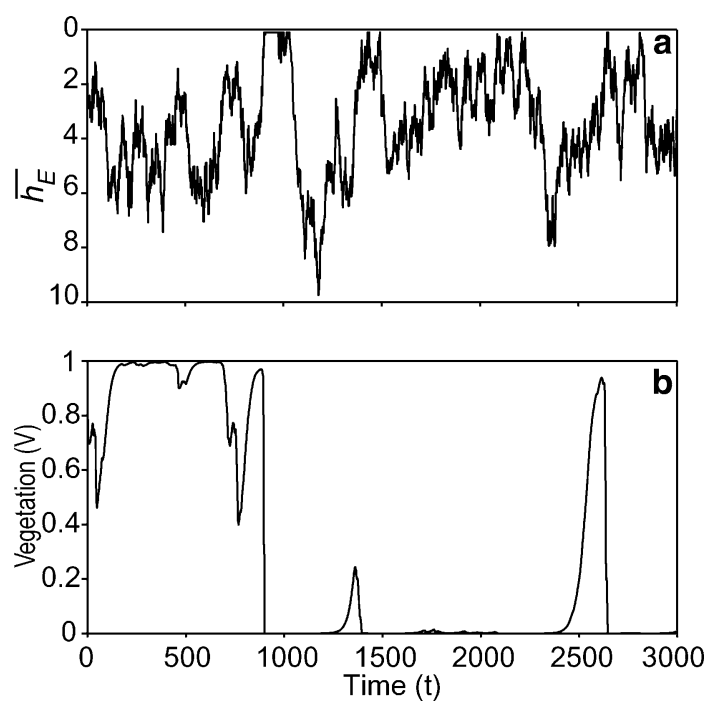

Figure 9. Example of the effect of random variations in water level (which is inversely related to the parameter $h_{E}$ ) (upper panel, generated as red noise on parameter $h_{E}$, $\lambda=100, \beta=0.3, \overline{h_{E}}=2$, values $<0.1$ were truncated to $0.1)$ on the occurrence of macrophytes (lower panel). Parameters: see Figure 6. 
Our model analysis suggests a less intuitive, but interesting alternative explanation for the observed difference between lakes in return time to the turbid state. The simulations show that if the system is pushed to a macrophyte-dominated state by drawdown, the return to the turbid state may take a long time, even if the turbid state is the only equilibrium. This delayed return to the macrophyte-poor state is due to the "ghost" of the macrophyte-rich equilibrium, which is the result of positive feedbacks that are too weak to stabilize the clear vegetated state in the long term but nevertheless may significantly delay the return to the turbid state with few submerged macrophytes.

The ghost theory implies that lakes remain longer in a transient vegetated state if growth conditions for macrophytes are more favorable. Therefore, the expectation for a large set of different lakes would be that upon drawdown some lakes will return quickly to the original (turbid) state, whereas others may linger for a long time around a (nearly stable) vegetated condition. This is well in line with the pattern of loss of macrophyte dominance in our lakes. It is especially interesting in this respect that small shifting lakes tended to remain longer in a transient vegetated state than larger ones (Figure 5). Our data and other studies suggest that such smaller lakes may well be systematically closer to having a stable vegetated state (Van Geest and others 2003; Jeppesen and others 1990; Søndergaard and others 2005; Scheffer and others 2006). Therefore, smaller lakes should be more likely to display ghost-effects and return to the turbid state only slowly after being pushed into a transient vegetated state by a disturbance. This fits well with the observed dynamics in our floodplain lakes.

Note that, even though fish dynamics are not explicitly included in our model, the role of fish in the dynamics of our lakes may well fit the ghost hypothesis in a broader sense. This is because the assumed negative effect of macrophytes on turbidity may hold also for their effect on fish (a notorious promotor of turbidity, besides its other negative direct and indirect impacts on macrophytes). Even if fish can freely enter the lakes during annual river floods, species that are characteristic of turbid water such as bream are known to avoid vegetated habitats (Perrow and Jowitt 1996; Scheffer 1998), and may well colonize macrophyte-dominated lakes less than turbid, macrophyte-poor lakes. Data from a set of interconnected shallow lakes in Belgium ("De Maten") confirm this possibility. In these lakes, temporary drawdown resulted in a transient increase in submerged macrophyte cover, while fish biomass strongly decreased and did not recover within two subsequent years, even though fish were able to migrate into these lakes (Van de Meutter and others 2006). Clearly, although our data do not allow analysis of patterns of remigration of fish into our lakes, it seems plausible that this is not a random process. The results in "De Maten" and numerous biomanipulation experiments (Meijer and others 1995; Meijer 2000) illustrate that fish are not merely 'drivers' of lake ecosystems but also respond to the state. Delayed recolonization by fish species that are typical of turbid lakes may thus be one of the mechanisms by which near-stable vegetation dominance can end up being a long transient state in some lakes.

In summary, our results suggest that a substantial portion of the lakes we studied are in a transient vegetated state much of the time. Low water levels appear to induce a shift of many turbid lakes into this transient state. The subsequent duration of the transient may be affected by stabilizing feed-back mechanisms of the macrophyterich state, even if this state is not stable. Our results are illustrative of the dominant role that transients can play in ecosystem dynamics (Hastings 2004). A practical implication of our findings is that hydrological regulation preventing drawdown may have been an important factor aggravating the permanent loss of submerged macrophytes due to cultural eutrophication.

\section{ACKNOWLEDGMENTS}

This project was financed by RIZA (Institute for Inland Water Management and Waste Water Treatment). We are grateful to John van Schie, Matthijs Rutten and Kirsten Vendrig for their assistance in the field.

\section{REFERENCES}

Blindow I, Andersson G, Hargeby A, Johansson S. 1993. Longterm pattern of alternative stable states in two shallow eutrophic lakes. Freshw Biol 30:159-67.

Buijse AD, Coops H, Staras M, Jans LH, Van Geest GJ, Grift RE, Ibelings BW, Oosterberg W, Roozen FCJM. 2002. Restoration strategies for river floodplains along large lowland rivers in Europe. Freshw Biol 47:889-907.

Coops H, Van Geest GJ. 2005. Extreme water-level fluctuations determine aquatic vegetation in modified large river floodplains. Arch Hydrobiol Suppl Large Rivers 15:261-74.

Engel S, Nichols SA. 1994. Aquatic macrophyte growth in a turbid windswept lake. J Freshw Ecol 9:97-109.

Gibbs GW. 1973. Cycles of macrophytes and phytoplankton in Pukepuke Lagoon following a severe drought. Proc N Z Ecol Soc 20:13-20. 
Grift RE, Buijse AD, Breteler JGPK, Van Densen WLT, Machiels MAM, Backx JJGM. 2001. Migration of bream between the main channel and floodplain lakes along the lower River Rhine during the connection phase. J Fish Biol 59:1033-55.

Hasselmann K. 1976. Stochastic climate models, part I: theory. Tellus 28:473-85.

Hastings A. 2004. Transients: the key to long-term ecological understanding? Trends Ecol Evol 19:39-45.

Havens KE, Sharfstein B, Brady MA, East TL, Harwell MC, Maki RP, Rodusky AJ. 2004. Recovery of submerged plants from high water stress in a large subtropical lake in Florida, USA. Aquat Bot 78:67-82.

Hough RA, Fornwall MD, Negele BJ, Thompson RL, Putt DA. 1989. Plant community dynamics in a chain of lakes: principal factors in the decline of rooted macrophytes with eutrophication. Hydrobiologia 173:199-217.

Jeppesen E, Jensen JP, Kristensen P, Søndergaard M, Mortensen E, Sortkjaer O, Olrik K. 1990. Fish manipulation as a lake restoration tool in shallow, eutrophic, temperate lakes. 2: Threshold levels, long-term stability and conclusions. Hydrobiologia 200-201:219-27.

Jeppesen E, Søndergaard Ma , Søndergaard Mo , Christoffersen K. 1997. The structuring role of submerged macrophytes in lakes. New York: Springer.

Jones JI, Sayer CD. 2003. Does the fish-invertebrate-periphyton cascade precipitate plant loss in shallow lakes? Ecology 84:2155-67.

Jongman RHG, Ter Braak CJF, Van Tongeren OFR. 1995. Data analysis in community and landscape ecology. Cambridge: Cambridge University Press.

Magnuson JJ, Tonn WM, Banerjee A, Toivonen J, Sanchez O, Rask M. 1998. Isolation vs. extinction in the assembly of fishes in small northern lakes. Ecology 79:2941-56.

McGowan S, Leavitt PR, Hall RI, Anderson NJ, Jeppesen E, Odgaard BV. 2005. Controls of algal abundance and community composition during ecosystem state change. Ecology 86:2200-11.

Meijer ML. 2000. Biomanipulation in the Netherlands-15 years of experience. Ph.D. Thesis. Wageningen University.

Meijer ML, Lammens EH, Raat AJP, Klein-Breteler JPG, Grimm MP. 1995. Development of fish communities after biomanipulation. Neth J Aquat Ecol 29:91-101.

Molls F. 1999. New insights into the migration and habitat use by bream and white bream in the floodplain of the River Rhine. J Fish Biol 55:1187-200.

Perrow MR, Moss B, Stansfield J. 1994. Trophic interactions in a shallow lake following a reduction in nutrient loading-a long-term study. Hydrobiologia 276:43-52.
Perrow MR, Jowitt AJD. 1996. The distribution of fish in relation tot macrophytes in Veluwemeer. Report to Rijkswaterstaat, RIZA, Lelystad, The Netherlands. ECON Ecological Consultancy. Norwich: University of East Anglia.

Roozen FCJM, Van Geest GJ, Ibelings BW, Roijackers R, Scheffer M, Buijse AD. 2003. Lake age and water level affect the turbidity of floodplain lakes along the lower Rhine. Freshw Biol 48:519-31.

Scheffer M, Hosper SH, Meijer ML, Moss B, Jeppesen E. 1993. Alternative equilibria in shallow lakes. Trends Ecol Evol 8:275-79.

Scheffer M. 1998. Ecology of shallow lakes. New York: Chapman \& Hall, 357.

Scheffer M, Van Geest GJ, Zimmer K, Jeppesen E, Sondergaard M, Butler MG, Hanson MA, Declerck S, De Meester L. 2006. Small habitat size and isolation can promote species richness: second-order effects on biodiversity in shallow lakes and ponds. Oikos 112:227-31.

Søndergaard M, Jeppesen E, Jensen JP. 2005. Pond or lake: does it make any difference? Arch Hydrobiol 162:143-65.

Strogatz SH. 1994. Nonlinear dynamics and chaos-with applications to physics, biology, chemistry and engineering. Reading: Addison-Wesley Publishing Company.

Tracy M, Montante JM, Allenson TE, Hough RA. 2003. Long-term responses of aquatic macrophyte diversity and community structure to variation in nitrogen loading. Aquat Bot 77:43-52.

Van Geest GJ, Wolters H, Roozen FCJM, Coops H, Roijackers RMM, Buijse AD, Scheffer M. 2005. Water-level fluctuations affect macrophyte richness in floodplain lakes. Hydrobiologia 539:239-48.

Van Geest GJ, Roozen FCJM, Coops H, Roijackers RMM, Buijse AD, Peeters ETHM, Scheffer M. 2003. Vegetation abundance in lowland floodplain lakes determined by surface area, age and connectivity. Freshw Biol 48:440-54.

Van Nes EH, Scheffer M, Van den Berg MS, Coops H. 2002. Dominance of charophytes in eutrophic shallow lakes-when should we expect it to be an alternative stable state? Aquat Bot 72:275-96.

Van Nes EH, Rip WJ, Scheffer M. 2007. A theory for cyclic shifts between alternative states in shallow lakes (this volume).

Van Nes EH, Scheffer M. 2005. Implications of spatial heterogeneity for regime shifts in ecosystems. Ecology 87:1797-807.

Van de Meutter F, Stoks R, De Meester L. 2006. Rapid response of macroinvertebrates to drainage management of shallow connected lakes. J Appl Ecol 43:51-60.

Wallsten M, Forsgren PO. 1989. The effects of increased water level on aquatic macrophytes. J Aquat Plant Manage 27:32-7. 